\title{
Protective Effect of Hydroalcoholic Extract of Solanum surattense on Brain Tissue Damage and Oxidative Stress in Adult Rats with Toxoplasmosis
}

\author{
Mansour Ataei ${ }^{1}$, Arash Khaki ${ }^{*}$, Yagoob Garedaghi ${ }^{3}$ \\ ${ }^{1}$ Faculty of Veterinary Medicine, Tabriz Branch, Islamic Azad University, Tabriz, Iran \\ ${ }^{2}$ Department of Pathobiology, Tabriz Branch, Islamic Azad University, Tabriz, Iran \\ ${ }^{3}$ Department of Parasitology, Tabriz Branch, Islamic Azad University, Tabriz, Iran
}

\begin{abstract}
Introduction: Toxoplasmosis is caused by a protozoan named Toxoplasma gondii. This protozoan is a parasite of cats that can spread among other animals and birds around the world and cause a disease that varies from mild to severe. The disease is seen in the forms of acquired toxoplasmosis and congenital toxoplasmosis. Many studies have shown that there is a relationship between reproductive function and toxoplasmosis. T. gondii has led to decreased reproductive performance of males and females in many experimental animals. The aim of this study was to investigate the protective effect of hydroalcoholic extract of Solanum surattense on the brain tissue damage and brain oxidative stress induced by $T$. gondii in adult rats.

Methods: For this purpose, 32 adult female rats were randomly divided into 4 groups. In group 1, 8 healthy rats received IP saline for 3 weeks. In group 2, 8 rats with T. gondii received IP saline for 3 weeks. In group 3, 8 rats with T. gondii received the hydroalcoholic extract of $S$. surattense for 3 weeks. In group 4, 8 healthy rats received the hydroalcoholic extract of $S$. surattense for 3 weeks. Then, brain tissue resection was performed to evaluate histological damage and levels of antioxidant enzymes.

Results: Histological and biochemical studies showed that $T$. gondii had a deleterious effect on the brain tissue of rats and increased the level of tumor necrosis factor- $\alpha(\mathrm{TNF}-\alpha)$ and interferon- $\gamma(\mathrm{IFN}-\gamma)$. The administration of hydroalcoholic extract of $S$. surattense improved these effects due to its high antioxidant properties.

Conclusion: The administration of the appropriate dose of hydroalcoholic extract of $S$. surattense for three consecutive weeks had a protective effect on brain tissue exposed to T. gondii.

Keywords: Solanum surattense extract, Toxoplasma gondii, Brain tissue injury, Oxidative stress, Hormonal injury.
\end{abstract}

Received: December 10, 2019, Accepted: December 19, 2019, ePublished: January 1, 2020

\section{Introduction}

Toxoplasmosis is caused by a protozoan named Toxoplasma gondii. This protozoan is a parasite of cats that can spread among other animals and birds around the world and cause a disease that varies from mild to severe $(1,2)$. The disease is seen in the forms of acquired toxoplasmosis and congenital toxoplasmosis. Many studies have shown that there is a relationship between reproductive function and toxoplasmosis. T. gondii has led to decreased reproductive performance of males and females in many experimental animals $(3,4)$. Many studies have shown that toxoplasmosis causes damage to brain tissue. T. gondii reduces brain function in humans and in many laboratory animals. Toxoplasmosis reduces the secretion of the hypothalamus, pituitary, and gonads. In fact, behavioral studies have gathered a great deal of evidence that latent toxoplasmosis causes motor dysfunction, learning and spatial memory deficits, anxiety, sensory disturbances, and changes in moral behavior $(5,6)$. Chronic infection may lead to the loss of gray matter cells in the brain. Parasites within neurons can directly cause the death of infected neurons or their atrophy, and inflammation may contribute to the death of neurons by producing nitric oxide and other toxic oxygen products (7). Today, natural products are widely used in the treatment of infections as well as brain and memory problems and disorders. Plant-based biomaterials have formed a branch of modern pharmacotherapy of diseases and have always been discussed as worthy alternatives to synthetic drugs due to their ease of access, reduced side effects, and reasonable prices, and have been of particular interest to researchers in recent decades (8-10). Solanum surattense is a plant belonging to the Solanaceae family, which is widely found in the southeastern region of Iran, especially in Sistan and Baluchestan province, and is known locally as Baluchi Tajrizi. Additionally, its antioxidant properties have been proposed. Studies have shown that oxidants activate caspases by producing free 
radicals. Caspases are activators of programmed cell death. Following the understanding of the mechanism of the effect of pathogens on vital tissues through oxidation and release of free radicals, an increasing and accelerated desire to recognize antioxidants has been felt and the bioactive substances in plant extracts have received much attention. Because they come from natural sources, they are naturally safe $(11,12)$. Due to the fact that studies have shown that the plant family Solanaceae has antioxidant properties and contains compounds such as lacton estriol, flavonoids, alkaloids, glycosides, and other antioxidant compounds and also considering that the non-toxicity of this plant in terms of blood and biochemical findings has been proven in previous studies, this study was done to investigate its effects as a safe substance.

\section{Materials and Methods}

For this purpose, 32 adult female rats were randomly divided into 4 groups. In group 1, 8 healthy rats received IP saline for 3 weeks. In group 2, 8 rats with T. gondii received IP saline for 3 weeks. In group 3, 8 rats with T. gondii received the hydroalcoholic extract of $S$. surattense for 3 weeks. In group 4, 8 healthy rats received the hydroalcoholic extract of $S$. surattense for 3 weeks. Then, brain tissue resection was performed to evaluate histological damage and levels of antioxidant enzymes.

\section{Results}

\section{Serum Level of Antioxidant Enzymes}

1. Serum Level of Malondialdehyde

Statisticalanalysis showed that thelevel of malondialdehyde (MDA) in the brain tissue of the T. gondii group was significantly higher compared to the control group $(P=0.000)$. Additionally, the level of MDA in the T. gondii group treated with $200 \mathrm{mg} / \mathrm{kg}$ of hydroalcoholic extract of $S$. surattense significantly reduced compared to the T. gondii group which received saline $(P=0.000)$. MDA levels were lower in the healthy group which received 200 $\mathrm{mg} / \mathrm{kg}$ of hydroalcoholic extract of $S$. surattense compared to the control group but the difference was not statistically significant $(P>0.05)$ (Figure 1$)$.

\section{Serum Levels of Superoxide Dismutase}

Statistical analysis showed that the level of superoxide dismutase (SOD) in the brain tissue of the T. gondii group was significantly lower compared to the control group $(P=0.000)$. Moreover, the level of SOD in the $T$. gondii group treated with $200 \mathrm{mg} / \mathrm{kg}$ of hydroalcoholic extract of $S$. surattense significantly increased compared to the $T$. gondii group which received saline $(P=0.001)$. SOD levels were higher in the healthy group that received $200 \mathrm{mg} /$ $\mathrm{kg}$ of hydroalcoholic extract of $S$. surattense compared to the control group but the difference was not statistically significant $(P>0.05)$ (Figure 2$)$.

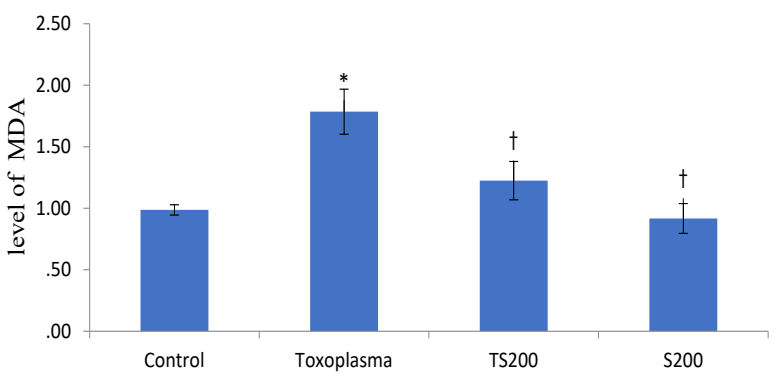

Figure 1. Level of Malondialdehyde in Brain Tissue. Symbol $(*)$ : Indicates that groups with ${ }^{*}$ are significantly different from groups of T. gondii. Group 1: Control group in which 8 healthy rats received IP saline for 3 weeks. Group 2: Toxoplasma group in which 8 rats received IP saline for 3 weeks. Group 3: TS200 group in which 8 rats with $T$. gondii received the hydroalcoholic extract of S. Surattense for 3 weeks. Group 4: S200 group in which 8 healthy rats received the hydroalcoholic extract of $S$. Surattense for 3 weeks.

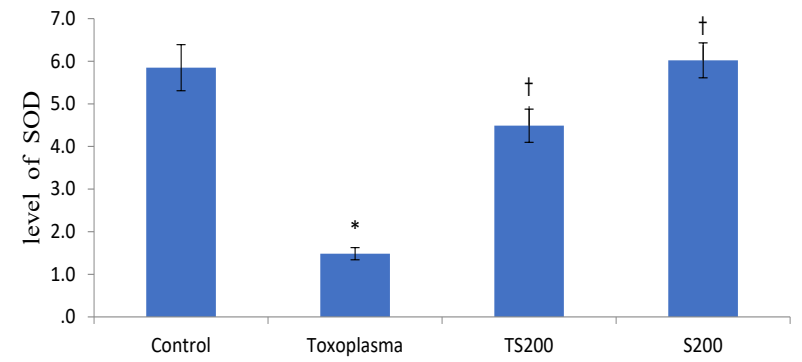

Figure 2. Superoxide Dismutase (SOD) Levels. Symbol (*): Indicates that groups with $*$ are significantly different from groups of $T$. gondii. Group 1: Control group in which 8 healthy rats received IP saline for 3 weeks. Group 2: Toxoplasma group in which 8 rats with T. gondii received IP saline for 3 weeks. Group 3: TS200 group in which 8 rats with $T$. gondii received the hydroalcoholic extract of S. surattense for 3 weeks. Group 4: S200 group in which 8 healthy rats received the hydroalcoholic extract of $S$. surattense for 3 weeks.

\section{Serum Levels of Glutathione Peroxide}

Statistical analysis showed that glutathione peroxide (GPX) level in the brain tissue of T. gondii group was significantly lower compared to the control group $(P=0.000)$. Moreover, the level of GPX in the T. gondii group treated with $200 \mathrm{mg} / \mathrm{kg}$ of hydroalcoholic extract of $S$. surattense was significantly higher compared to $T$. gondii group which received saline $(P=0.001)$. GPX level increased in the healthy group which received $200 \mathrm{mg} /$ $\mathrm{kg}$ of hydroalcoholic extract of S. surattense compared to the control group but the difference was not statistically significant $(P>0.05)$ (Figure 3$)$.

\section{Brain Tissue Histology Results in Study Groups}

In histological studies, degenerative brain lesions and bleeding were observed in the tissue of the rats with $T$. gondii. The cross-section of the brain tissue in the group which received hydroalcoholic extract of $S$. surattense showed less damage and bleeding compared to the T. gondii group which received saline. In histological examinations, 
in the control group, brain tissue was reported to be completely normal and without any damage, and also in the healthy group which received the extract, the brain tissue was reported to be completely healthy (Figure 4).

\section{Discussion}

Toxoplasma gondii is an obligate intracellular protozoa belonging to the phylum of Apicomplexa. Infection with this parasite has spread worldwide, ranging from mild to severe, in humans and various types of animals. This parasite is found in the gut of cats and felines but has the ability to infect many warm-blooded animals, including mammals and birds, which are considered to be the intermediate hosts of this protozoan $(13,14)$. The disease caused by this parasite is called "toxoplasmosis" which is seen in humans in both congenital and acquired

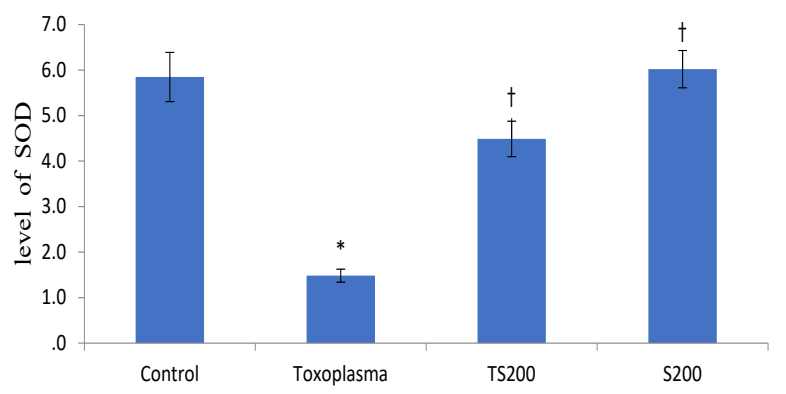

Figure 3. Serum Levels of Glutathione Peroxide. Symbol (*): Indicates that groups with * are significantly different from groups of T. gondii. Group 1: Control group in which 8 healthy rats received IP saline for 3 weeks. Group 2: Toxoplasma group in which 8 rats with Toxoplasma gondii received IP saline for 3 weeks. Group 3: TS200 group in which 8 rats with T. gondii received the hydroalcoholic extract of the $S$. surattense for 3 weeks. Group 4: S200 group in which 8 healthy rats received the hydroalcoholic extract of $S$. surattense for 3 weeks.
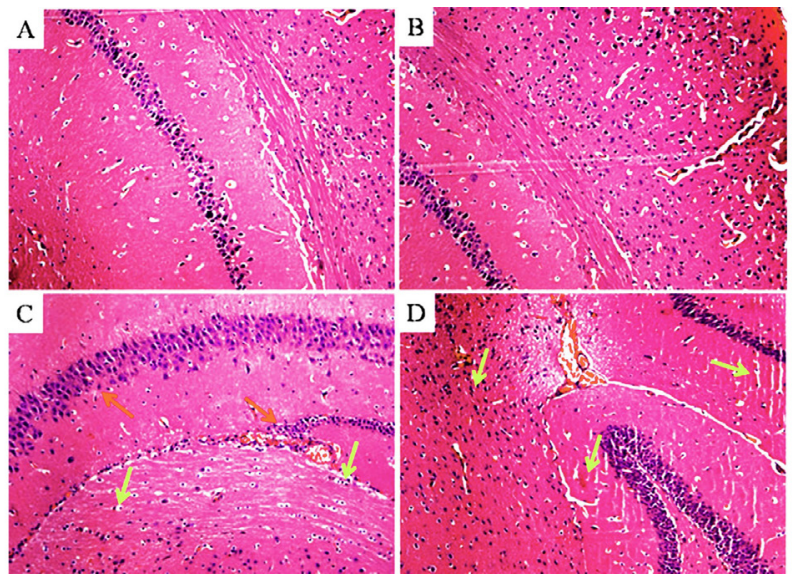

Figure 4. Brain Histology Image of the Study Groups (Hematoxylin and Eosin Staining). A. The microscopic image of brain tissue belonging to the control group. B. The microscopic image of brain tissue belonging to the healthy group that received the extract. C. The microscopic image of brain tissue belonging to the Toxoplasma group that received saline. D. The microscopic image of brain tissue belonging to the Toxoplasma group that received the extract. forms. In adults, it is usually asymptomatic and rarely causes severe disease. In histological studies, degenerative brain lesions and bleeding were observed in the tissue of the rats with $T$. gondii $(15,16)$. The cross-section of brain tissue in the group that received the hydroalcoholic extract of $S$. surattense showed less damage compared to the Toxoplasma group and the amount of bleeding was observed to be less. Due to the fact that Toxoplasma infection causes oxidative stress, it can cause damage to brain tissue (17-19).

Numerous studies have been performed in this field, which show that $T$. gondii infection causes oxidative stress and as a result, the activity of antioxidants such as SOD and GPX decreases and MDA production increases due to lipid peroxidation $(20,21)$.

The present study showed that the administration of $S$. surattense extract by preventing the induction of oxidative stress and increasing the activity of antioxidants causes a balance in the production and activity of antioxidants against the production of reactive oxygen species. As a result, it prevents the decrease of SOD and GPX levels and the increase of MDA, thereby preventing damage to the brain tissue by inhibiting oxidative stress. Furthermore, the administration of this extract regulated the serum level of reactive oxygen species and the reason could be its antioxidant effect.

\section{Conclusion}

The administration of the appropriate dose of hydroalcoholic extract of $S$. surattense had a protective effect on histological damage and oxidative stress due to T. gondii infection in rat brain tissue and it also regulated the level of oxidative stress markers and improved brain activity in these rats. Finally, it is suggested that further studies be done in this field and in other studies and the expression level of other genes such as interleukins should be measured.

\section{Conflict of Interests}

The authors declare that they have no conflict of interests.

\section{Ethical Issues}

In this research, ethical considerations have been fully observed.

\section{Acknowledgments}

This study was conducted in the form of a doctoral dissertation at the Islamic Azad University, Tabriz, Iran.

\section{Authors' Contribution}

AKH did writing and editing of the manuscript. MA designed and did data collection. YG designed, did data collection and statistical analysis.

\section{Funding}

This research was conducted with the support of the Vice Chancellor for Research and Technology of the Islamic Azad University, Tabriz Branch.

\section{References}

1. Dubey JP, Beattie C. Toxoplasmosis of Animals and Man. 
London: CRC Press; 1988.

2. Montoya JG, Liesenfeld O. Toxoplasmosis. Lancet. 2004;363(9425):1965-76. doi: 10.1016/s01406736(04)16412-x.

3. Ruskin J, Remington JS. Toxoplasmosis in the compromised host. Ann Intern Med. 1976;84(2):193-9. doi: 10.7326/0003-4819-84-2-193.

4. Shoorei H, Khaki A, Khaki AA, Hemmati AA, Moghimian $M$, Shokoohi M. The ameliorative effect of carvacrol on oxidative stress and germ cell apoptosis in testicular tissue of adult diabetic rats. Biomed Pharmacother. 2019;111:568-78. doi: 10.1016/j.biopha.2018.12.054.

5. Shoorei $H$, Banimohammad $M$, Kebria MM, Afshar $M$ Taheri MM, Shokoohi M, et al. Hesperidin improves the follicular development in 3D culture of isolated preantral ovarian follicles of mice. Exp Biol Med (Maywood). 2019;244(5):352-61. doi: 10.1177/1535370219831615.

6. Shokoohi M, Khaki A, Shoorei H, Khaki AA, Moghimian M, Abtahi-Eivary SH. Hesperidin attenuated apoptoticrelated genes in testicle of a male rat model of varicocoele. Andrology. 2020;8(1):249-58. doi: 10.1111/ andr.12681.

7. Halliwell B. Oxidative stress and cancer: have we moved forward? Biochem J. 2007;401(1):1-11. doi: 10.1042/ bj20061131.

8. Gems D, Partridge L. Stress-response hormesis and aging: "that which does not kill us makes us stronger". Cell Metab. 2008;7(3):200-3. doi: 10.1016/j. cmet.2008.01.001.

9. Prandota J. Autism spectrum disorders may be due to cerebral toxoplasmosis associated with chronic neuroinflammation causing persistent hypercytokinemia that resulted in an increased lipid peroxidation, oxidative stress, and depressed metabolism of endogenous and exogenous substances. Res Autism Spectr Disord. 2010;4(2):119-55. doi: 10.1016/j.rasd.2009.09.011.

10. Elsheikha HM, El-Motayam MH, Abouel-Nour MF, Morsy AT. Oxidative stress and immune-suppression in Toxoplasma gondii positive blood donors: implications for safe blood transfusion. J Egypt Soc Parasitol. 2009;39(2):421-8

11. Soares $C$, de Sousa A, Pinto A, Azenha M, Teixeira J Azevedo RA, et al. Effect of 24-epibrassinolide on ROS content, antioxidant system, lipid peroxidation and $\mathrm{Ni}$ uptake in Solanum nigrum L. under Ni stress. Environ Exp Bot. 2016;122:115-25. doi: 10.1016/j.envexpbot.2015.09.010.

12. Sesti F, Liu S, Cai SQ. Oxidation of potassium channels by ROS: a general mechanism of aging and neurodegeneration? Trends Cell Biol. 2010;20(1):45-51. doi: 10.1016/j.tcb.2009.09.008.

13. Abamecha F, Awel H. Seroprevalence and risk factors of Toxoplasma gondii infection in pregnant women following antenatal care at Mizan Aman General Hospital, Bench Maji Zone (BMZ), Ethiopia. BMC Infect Dis. 2016;16(1):460. doi: 10.1186/s12879-016-18066.

14. Alvarado-Esquivel C, Estrada-Martínez S, Liesenfeld O. Toxoplasma gondii infection in workers occupationally exposed to unwashed raw fruits and vegetables: a case control seroprevalence study. Parasit Vectors. 2011;4:235. doi: 10.1186/1756-3305-4-235.

15. Alvarado-Esquivel C, Rascón-Careaga A, Hernández-Tinoco J, Corella-Madueño MA, Sánchez-Anguiano LF, Aldana-Madrid ML, et al. Seroprevalence and associated risk factors for Toxoplasma gondii infection in healthy blood donors: a cross-sectional study in Sonora, Mexico. Biomed Res Int. 2016;2016:9597276. doi: 10.1155/2016/9597276.

16. Hussain MA, Stitt V, Szabo EA, Nelan B. Toxoplasma gondii in the Food Supply. Pathogens. 2017;6(2). doi: 10.3390/ pathogens6020021.

17. Iddawela D, Vithana SMP, Ratnayake C. Seroprevalence of toxoplasmosis and risk factors of Toxoplasma gondii infection among pregnant women in Sri Lanka: a cross sectional study. BMC Public Health. 2017;17(1):930. doi: 10.1186/s12889-017-4941-0.

18. Nahouli H, El Arnaout N, Chalhoub E, Anastadiadis E, El Hajj H. Seroprevalence of anti-Toxoplasma gondii antibodies among Lebanese pregnant women. Vector Borne Zoonotic Dis. 2017;17(12):785-90. doi: 10.1089/vbz.2016.2092.

19. Tegegne D, Abdurahaman M, Mosissa T, Yohannes M. AntiToxoplasma antibodies prevalence and associated risk factors among HIV patients. Asian Pac J Trop Med. 2016;9(5):460-4. doi: 10.1016/j.apjtm.2016.03.034.

20. Gharadaghi Y, Shojaee S, Khaki A, Rastegar H. Modulating effect of Allium cepa on kidney apoptosis caused by Toxoplasma gondii. Int J Pharm Teach Pract. 2012;3(4):412-7.

21. Liu Q, Wang ZD, Huang SY, Zhu XQ. Diagnosis of toxoplasmosis and typing of Toxoplasma gondii. Parasit Vectors. 2015;8:292. doi: 10.1186/s13071-015-0902-6.

(c) 2020 The Author(s); This is an open-access article distributed under the terms of the Creative Commons Attribution License (http:// creativecommons.org/licenses/by/4.0), which permits unrestricted use, distribution, and reproduction in any medium, provided the original work is properly cited. 